\title{
QUALITY ASSURANCE TESTS FOR ADHESION OF PAINT ON TACTICAL RIGID WALL SHELTERS
}

\section{Hiroshi Watanabe* Larry W. Masters James F. Seiler, Jr.}

\section{U.S. DEPARTMENT OF COMMERCE National Institute of Standards and Tochnology Natlonal EngIneering Laboratory Center for Bullding Technology Galthersburg, MD 20899}

\section{* Guest Researcher from Takenaka} Corporatlon, Tokyo, Japan

Prepared for:

U.S. Army Natick Research, Development and Englneering Center Tactlcal Shelters Branch Natlck, MA 01760

U.S. DEPARTMENT OF COMMERCE Robert A. Mosbacher, Secretary NATIONAL INSTITUTE OF STANDARDS AND TECHNOLOGY

John W. Lyons, Director 



\section{QUALITY ASSURANCE TESTS FOR ADHESION OF PAINT ON TACTICAL RIGID WALL SHELTERS}

\section{Hiroshi Watanabe* Larry W. Masters James F. Seiler, Jr.}

U.S. DEPARTMENT OF COMMERCE Natlonal Instltute of Standards and Technology National Englneerlng Laboratory Center for Bullding Technology Galthersburg, MD 20899

* Guest Researcher from Takenaka Corporation, Tokyo, Japan

\section{Prepared for:}

U.S. Army Natlck Research, Development and Englneerlng Center Tactlcal Shelters Branch Natlck, MA 01760

January 1990

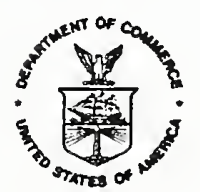



This document was prepared at the request of the U.S. Army Natick Research, Development and Engineering Center to provide assistance in identifying or developing a better method(s) for assuring the adequacy of paint adhesion on aluminum-faced sandwich panels of portable rigid wall shelters. The preferred requirements developed for the quality assurance tests are that the tests be quantitative, reliable, suitable for in-situ testing, low cost, and non-destructive.

Currently available methods were surveyed. Both destructive and non-destructive techniques were examined. Among them, a button pull-off test was found to be most advantageous. Preliminary laboratory experiments using a button pull-off test to measure the bond strength of painted specimens provided by a shelter manufacturer showed the average bond strength of the exterior and the interior paints to be $7.27 \mathrm{Mpa} \mathrm{(1050} \mathrm{psi)} \mathrm{and} \mathrm{9.29} \mathrm{Mpa} \mathrm{(1350}$ psi), respectively. Other experiments examined the feasibility of a semi-nondestructive button pull-off techniques, which, by using certain materials to reduce the adhesive/paint bond strength, was capable of testing a paint without damaging it. Two of the three "bond controllers" tested were found to be effective.

The recommendations for future research include: 1) establishing a technical basis for a minimum acceptable bond strength of paint; 2) developing and standardizing a improved button pulloff test; and 3) carrying out a feasibility study on nondestructive methods.

Key Words: adhesion; adhesion tests; bond strength; paint; tactical rigid wall shelters; test methods 



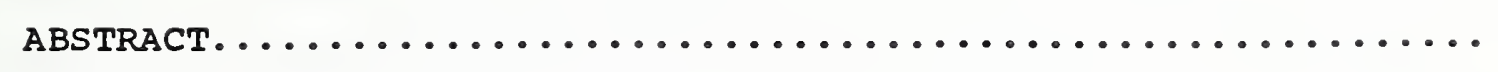

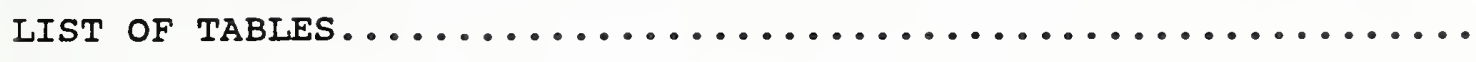

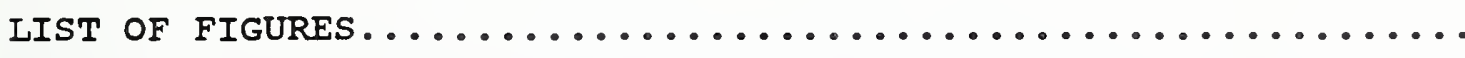

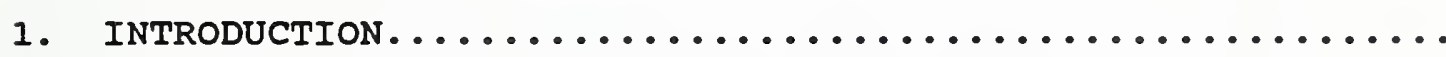

2. CRITERIA FOR TESTS THAT ASSURE THE ADEQUACY OF

PAINT ADHESION.................................. 2

3. CURRENTLY AVAILABLE METHODS.......................... 3

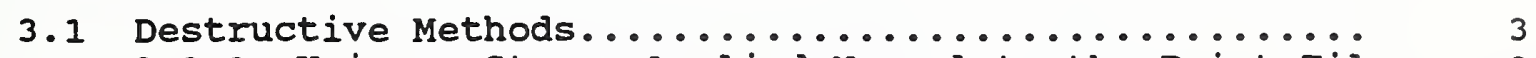
3.1.1 Using a Stress Applied Normal to the Paint Film 3 3.1.2 Using a Stress Applied Parallel to the Paint Film 6

3.2 Non-destructive Methods........................ 7

3.3 Conclusions on Available Methods.................. 10

4. RESULTS OF PRELIMINARY LABORATORY ASSESSMENTS............ 11

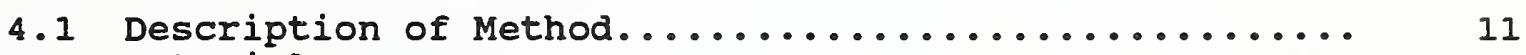

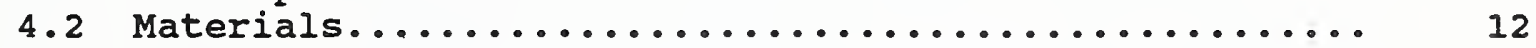

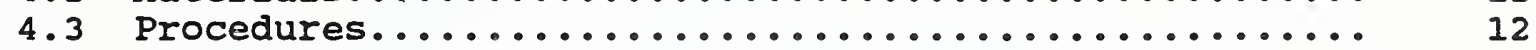

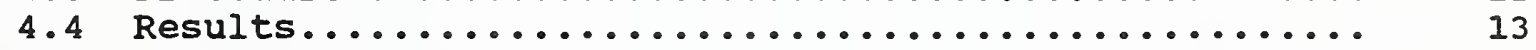

5. PRELIMINARY ASSESSMENT OF A SEMI-NONDESTRUCTIVE PULL-OFF TEST 16

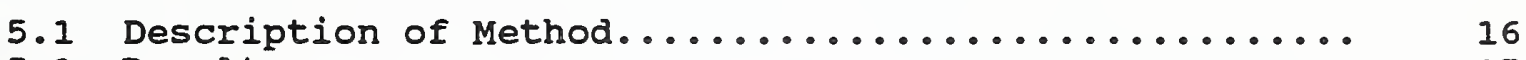

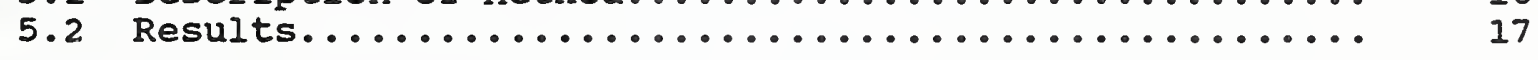

6. SUMMARY AND CONCLUSIONS.............................. 19

7. RECOMMENDATIONS FOR FUTURE RESEARCH.................... 20

8. ACKNOWLEDGEMENTS................................. 22

9. REFERENCES....................................... 22 

Table 1. Destructive Test Methods to Evaluate Bond Strength of Paints. 25 Table 2. Non-destructive Test Methods to Evaluate Bond Quality

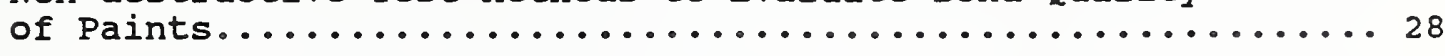

Table 3. Bond Strength of Exterior Paint Measured by Pull-off Test.... 29

Table 4. Bond Strength of Interior Paint Measured by Pull-off Test.... 30 Table 5. Results of Experiments for semi-nondestructive Pull-off Test..31

\section{LIST OF FIGURES}

Figure 1. Fixed-alignment Adhesion Tester for Pull-off Test............32 Figure 2. Self-aligning Adhesion Tester for Pull-off Test..........32 Figure 3. Test Assemblies Presented in Iso standard $\# 4624 \ldots \ldots \ldots \ldots$

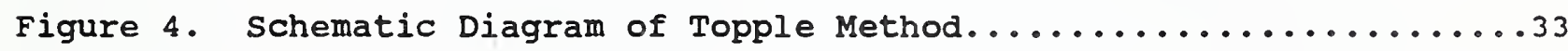
Figure 5. Classification of Adhesion Test Results for Cross-Cut Test

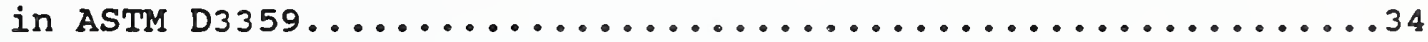

Figure 6. Example of Blister Test Configuration................... Figure 7. Balanced-Beam Scrape-Adhesion Tester....................

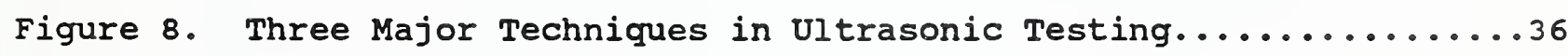
Figure 9. Schematic Diagram of Pull-off Test........................

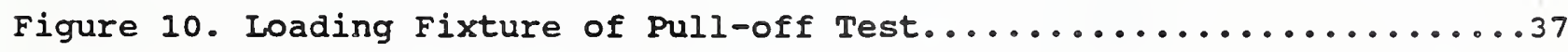

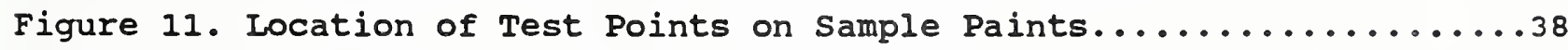

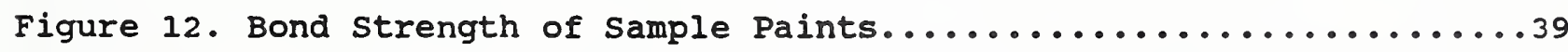
Figure 13. Histogram of Measured Bond Strengths of Sample Paints......40 



\section{INTRODUCTION}

The U.S. Army uses a range of tactical rigid wall shelters in situations requiring highly mobile work facilities for living or storage. The exteriors and interiors of the aluminum-faced shelters are painted during the manufacturing process. To help ensure the adequacy of the paint adhesion, scratch and tape pulloff or the knife lift tests are performed after the paint has cured. These tests have a number of shortcomings: 1) they are destructive; 2) they provide only qualitative or subjective data; and 3 ) they are not fully responsive to the needs of the Army in assuring bond strength. There is a need to identify or develop an improved test method, or a series of test methods, for assessing the adequacy of paint adhesion.

The U.S. Army Natick Research, Development and Engineering Center requested the National Institute of Standards and Technology (NIST) to:

1) identify the essential and desirable attributes of tests to assure the adequacy of paint adhesion;

2) assess the current state of technology of tests that measure the bonding quality of protective paints and determine how they relate to the essential and desirable attributes identified;

3) perform preliminary laboratory tests of promising methods; and

4) recommend needs for future research.

This report presents the findings of this study. 
2. CRITERIA FOR TESTS THAT ASSURE THE ADEQUACY OF PAINT ADHESION

Criteria for tests that assure the adequacy of paint adhesion reflect both essential and desirable attributes.

Essential attributes include:

1) able to determine adequacy of adhesion of the Chemical Agent Resistant coating (CARC) system used for painting aluminumfaced sandwich panels;

2) reproducible;

3) low cost per test;

4) ease of use;

5) speed;

6) operator independent; and

7) safe.

Desirable attributes include:

1) non-destructive;

2) quantitative in the sense that adhesion is measured relative to a minimum acceptable value ( a go/no-go method is ultimately desired);

3) applicable to both flat and curved surfaces; and

4 ) provides information on failure mode. 


\section{CURRENTLY AVAILABLE METHODS}

This chapter presents a summary of currently available methods to evaluate the adequacy of the bonding of paints to the substrate and an assessment of the ability of methods to comply with the foregoing criteria. In addition, comments are given on each method in terms of its adaptability to in-situ bond evaluation of CARC paint on shelters.

Many measurement techniques may, in principle, be useful for evaluating paint adhesion. Some of these techniques are relatively new and need to be studied for use in-situ measurements; some have been extensively studied; and some have been standardized. In this chapter, the methods or measurement techniques are divided into two groups: destructive methods and non-destructive methods.

\subsection{Destructive Methods}

There are two types of destructive methods:

1) A stress is applied normal to the painted surface and the critical stress level when the paint is detached is measured; and

2) A stress is applied parallel to the painted surface and the critical stress when the paint is detached is measured. Table 1 presents descriptions of the destructive methods and comments on them.

\subsubsection{Using a Stress Applied Normal to the Paint Film}

Five methods were identified which rely upon destructive detachment of the paint from the substrate: 1) the button pull-off test; 2) the moment (topple) test; 3) the tape test; 4) the blister test; and 5) the ultracentrifugal method.

The button pull-off test has been studied by a number of researchers [1-3]. The applied load at failure is used as a measure of "bond 
strength" of the paint to the substrate. A notable advantage of the pull-off method is that the locus of failure indicates the weakest plane in the paint system. The time required for testing with the procedure depends on the cure properties of the adhesives used. Since the button pull-off test is a commonly used method, the results of non-destructive methods are often compared to the "bond strength" measured with the pull-off method in order to find a correlation between the two. The properties of the adhesive used to bond the button to the paint are key factors affecting the results of the method. The maximum measurable stress is limited by the bond strength between the button and the adhesive. On the other hand, solvents in the adhesive may affect the paint. Therefore, adhesive selection is a crucial part in carrying out this test. In practice, epoxy-based adhesives have been most frequently used because they are fast-setting, are compatible with most of painted surfaces, and provide sufficient bond strengths for the test method.

Another important factor is the coaxial alignment of the test assembly to ensure the resultant force is normal to the surface. If this is not satisfied, the test results tend to be low because of stress concentration at an edge of the attachment. ASTM D-541 [4] specifies the test procedure and presents a standard configuration for pull-off testing of paints; in the annexes of the standard, two portable testers are introduced. One is a fixed-alignment type (Figure 1), which is small and apparently easy to use. The other is a self-aligning pneumatic adhesion tester, which needs compressed air to operate (Figure 2). Since the alignment affects the reproducibility of the data, the selfaligning tester is expected to yield more reliable results.

International Organization for standardization (ISO) standard \#4624 [5] presents two pull-off test assemblies for use with a laboratory tensile testing machine as illustrated in Figure 3. Assembly $A$ is for both rigid and deformable substrates and is designed to prevent stress concentrations due to deformation of 
the substrate during a test. Assembly B is suitable for rigid substrates only. An experimental study measured the bond strength of several paints with Assembly A and Assembly B [3]. The results showed that Assembly B gave values 20 to 60 percent less than Assembly A for the same paints. The study also indicated that the test results, i.e., strength and locus of failure, were dependent on the diameter and rigidity of the attachments.

Figure 4 illustrates a test assembly of the moment (topple) test. In principle, the method is similar to the pull-off test, the only difference being the means of producing a perpendicular force on the paint surface. Therefore, it has the same advantages and restrictions as the pull-off test. Few papers have been written on this technique [2].

The tape test is one of the most widely adopted techniques for evaluating adhesion of paint to the substrate. The test procedure consists of cutting the paint with a sharp blade, placing adhesive tape on the cut, and removing the tape. several variations of this method have been described by researchers [1, 2, 6, 7]. ASTM standard D3359 [8] specifies two test methods as described in Table 1. In this standard, a six-level classification is given to the $\mathrm{X}$-cut method for evaluating the test results. The scale begins from " $5 \mathrm{~A}$ " to represent no peeling or removal and ends at "OA" to represent removal beyond the area of the $\mathrm{X}$. Thus, the record of the test results are expressed semiquantitatively. In the cross-cut tape test, a classification based on the percentage of the area affected is presented (Figure 5). The tape tests are comparatively simple and are relatively inexpensive to perform. Expertise is necessary to maintain repeatability and reproducibility in utilizing the method and the tests are therefore operator dependent. As is the case with the adhesive in the pull-off test, the adhesive strength of the tape to the paint adhesion limits the maximum measurable level of paint to the substrate bond. The paints under test experience 
stress parallel to the surface before being pulled by a tape. This lateral stress causes detachment to some extent. On the other hand, the lateral force is dependent on the paint thickness, which is why the ASTM standard specifies different spaces between the grids ( $1 \mathrm{~mm}$ or $2 \mathrm{~mm}$ ) according to the paint thickness. The tape test does not provide data for comparing the bond adequacy of paints with different thicknesses because the test results are dependent on the paint thickness.

The blister test (Figure 6) and the ultracentrifugal method are excellent in precision in measuring the ultimate stress at the time of detachment. Both tests, however, require expensive apparatus and samples cut from the object to be tested.

\subsubsection{Using a Stress Applied Parallel to the Paint Film}

The following methods are designed to produce shear stress at the bond line, thus causing detachment from the substrate. One issue which arises from the application of the stress is whether or not such a stress can represent the bond adequacy of paints. Another issue stems from the fact that, in practice, it is difficult to produce shear stress alone; deformations caused by other stresses are likely to occur. Therefore, the results obtained are subject to such factors as paint thickness, substrate stiffness, and abrasion coefficient.

The lap-shear method is the simplest among these tests, but few studies [9] have been carried out using this technique on paints.

In the ring-shear method, specimen paints applied on a cylinder with a predetermined width are forced against a die to receive a shear stress [10]. This technique requires a thick paint film applied with a precise thickness on a rod. It is not possible to test paints on a flat substrate.

The indentation test and the scratch test employ the same basic 
principle: they aim to measure the stress at which the paint film breaks due to shear force. In the indentation test, an indenter is pushed against the paint film to cause a shear force. A stylus is pulled across the paint surface with increasing force in the scratch test. The indentation test can be carried out with a conventional hardness tester. It is reported that the results are dependent on the shape of the stylus point and on the hardness of the substrate [10]. Fewer studies have been carried out on the indentation test than on the scratch test. ASTM D2197 [11] specifies the standard scratch test method and presents an apparatus, "Balanced-beam scrape-adhesion tester", shown in Figure 7. The standard states that the sample under test should be a horizontal plate.

\subsection{Non-destructive Methods}

Most of the non-destructive test methods are intended to detect abnormalities which exist inside the sample tested, such as the defects at the bond line of the paint to the substrate. Evaluating the paint bond to the substrate addresses the so-called subsurface defects. However, a goal of non-destructive paint evaluation tests is to estimate bond strength, rather than detecting defects. Except for a few instances, this goal has seldom been attained. Table 2 describes the non-destructive methods which are applicable to paint bond evaluation.

Ultrasonic testing has found a diversity of applications in nondestructive evaluation. These techniques can be divided into three groups according to the principle of the method involved [13]:

1) Transmission method;

2) Resonance technique; and

3) Pulse-echo technique.

Schematic diagrams of the methods are shown in Figure 8. 
In the transmission method, defects in the path of an ultrasonic beam cast an "acoustic shadow" on the receiver, thus indicating the presence of the defect. Although the theory is simple, the technique poses many practical difficulties in locating flaws. The causes of the difficulties include diffraction around the edges of the defect, resonance which results in variations in the intensity of the signal received, and the absence of consistent acoustic coupling.

In the resonance technique, the resonance phenomenon of plates is used to measure sample thickness. A variation of this technique is applied in the Fokker Bond Tester [14], which is designed to evaluate bond strength in adhesive joints of plates. This method will be discussed later in the report.

In the pulse-echo technique, a short burst of ultrasonic waves is sent into the object and the waves are reflected back to the detector. Discontinuities, defects, or boundaries of the object have different reflection patterns than the bulk matrix, and the interference patterns are displayed on an oscilloscope. When testing painted surfaces, one limiting factor is pulse length. The shortest wavelength available is on the order of $0.1 \mathrm{~mm}$ (0.004 inches). Thus, defects under paints of typical thickness for shelters -- no more than $0.1 \mathrm{~mm}$-- are undetectable. Therefore, special techniques are required to overcome the difficulty. If the problem concerning wavelength or the resolution in the direction of depth is solved, the pulse-echo method may prove to be a valuable method [15].

The Fokker Bond Tester, which is a variation of the resonance method, was developed by an aircraft maker [14]. By using the phenomenon that a variation in resonance frequency correlates with the shear strength of the lap joints, the tester estimates shear strength of adhesively-bonded lap joints of plates. To date, this tester seems to be the only practical industrial 
device for evaluating bond strength, and has been used in assembly lines in an aircraft factory. Attempts were made to apply the Fokker Bond Tester to the evaluation of paint adhesion on six types of specimens [16]. The paint films were relatively thick, ranging from 0.06 to $1.3 \mathrm{~mm}$. A-scale values, which represent the transition of resonance frequency in the tester, were compared with the results of the pull-off test. The conclusion was that A-scale correlated with the difference in locus of failure (i.e., adhesive or cohesive) but that the tester was not able to estimate the bond strength as measured with the pull-off test.

The laser pulse method is another variation of ultrasonic (or acoustic) testing. In this technique, laser pulses, instead of acoustic transducers, activate the surface of the sample. The application of laser pulses is expected to overcome the limitation caused by the use of transducers and to enable detection with high frequency [17]. Shortcomings include: the dependency of results on surface conditions; the requirement that the configuration be precise with little micro-vibration; an the need for access to the back side of the substrate. These limitations restrict application of the technique to laboratory use and to the detection of the bond of metallic coatings.

In infrared thermography, thermal discontinuities, which usually stem from defects, are detected as local differences in surface temperature. This technique includes generating heat flow through the object to be tested to produce a temperature difference. Thermography is advantageous in testing large areas. Some techniques have been presented for detecting delamination of layered materials or voids in solid materials. But it has not been determined if thermography is effective in detecting the quality of paint bond $[18,19]$. 


\subsection{Conclusions on Available Methods}

When priority for an adhesion test method is put on "quantitative" and "in-situ" measurements, the button pull-off test best meets the requirements. The most advantageous point of this test method is that the results provide a quantitative measure of bond strength. Further, the refinement made through standardization of the technique, in terms of equipment and test procedure, has reduced the problems in practical use, e.g., alignment, portability of the tester and adhesives to bond an attachment. However, the selection and application of the adhesives to best suit the paints to be tested need investigation.

Among the non-destructive methods studied, ultrasonic methods have the greatest potential for evaluating bond adequacy. other methods evaluate disbonding or voids. A spectrum analysis of received waves, a variation of the pulse echo technique, should be investigated further even though the method has unavoidable disadvantages in practical use. Most of the disadvantages are related to the use of transducers and coupling media. For the in-situ application of the method, these problems have to be solved.

Infrared thermographic techniques developed to date do not provide information on the adequacy or strength of bond. However, the potential of the method to rapidly detect defects over relatively large areas is a unique and practical advantage. 
4. RESULTS OF PRELIMINARY LABORATORY ASSESSMENTS

A series of preliminary experiments were carried out to measure the bond strength (as indicated by the level of applied load at failure) of paint samples provided by a shelter manufacturer and to examine the most promising method for paint bond assessment, i.e., the button pull-off test.

\subsection{Description of Method}

The experiments were carried out according to the pull-off method specified in ASTM D4541, "Standard Method for Pull-off Strength of Coatings Using Portable Adhesion Testers." The apparatus used consisted of:

1) a detachable stainless steel button having a cylindrical base of $10.6 \mathrm{~mm}$ (0.42 inches) in diameter;

2) a central grip for engaging the button through an annular base that is forced away from the grip by the interaction of a self-aligning seal;

3) a pressure gage and a rate controller that is connected to a flexible hose to supply pressurized air to the button; and

4) a compressed air tank.

A schematic diagram of the apparatus is illustrated in figure 9.

The reliability of data obtained with this method is subject to a number of factors. For example, the rigidity of the substrate may affect the test results as mentioned in section 3 . This technique is not suitable for paints applied on a deformable substrate, because deformation will cause stress concentrations in the perimeter of the tested area. This may result in a low load due to the premature failure caused by the stress concentrations. To minimize the effect of substrate deformation, we reinforced the painted test specimen as described later and used buttons 
with a small diameter.

\subsection{Materials}

Ten samples of painted aluminum, $300 \mathrm{~mm} \times 300 \mathrm{~mm} \times 1 \mathrm{~mm}$ thick, were obtained from a shelter manufacturer. A green exterior paint had been applied by the manufacturer on one side of each sample, and a white interior paint on the other. The substrate was an aluminum alloy, which is the same material as the skin in rigid wall panels of the shelters. Two panels were selected Which had comparatively even paint thickness across the surface. They were glued to 19 mm-thick (0.75 inches) plywood with epoxybased adhesive so that their rigidity approximated that of the sandwich panels. An epoxy-based adhesive was used to attach buttons to the paints.

\subsection{Procedures}

The typical procedure for the experiment was to:

1) Mark the points to be measured on the sample surface with a pencil;

2) Clean the paint surface and the base of the button with ethyl alcohol and air dry the cleaned surface;

3) Glue a button on the paint;

4) Cure the adhesive at $70^{\circ} \mathrm{C}$ for four hours,

5) Position the annular ring on the paint concentric with the button and set the button to it;

6) Initialize the system by nulling the pressure indicator and introducing a small amount of gas in order to set the seal and align the device;

7) Set the load rate at $0.34 \mathrm{Mpa} / \mathrm{s}$ (50 psi/s) and begin loading;

8) Record the maximum pressure indicated by the pressure gauge and calculate the stress at the failure; and

9) Observe and record the locus of failure. 
Buttons were adhered to the paints in two different ways (Figure 10).

Method I:

The paint to be tested was cut through to the substrate along the edge of the button prior to adhering. Excess adhesive was removed by a plastic applicator to ensure that the area to be tested was separated from the adjacent paint.

Method II:

A sheet of paper having a circular opening with the same diameter as the button was placed on the paint. Adhesive was applied on the bottom of the button and the button was placed exactly within the opening. The paper containing the excess adhesive was removed.

Three sets of five measurements were made on each test panel;

thus a total of 15 measurements were made on both the green and white paints. The location of the test points is shown in Figure 11.

\subsection{Results}

Table 3 presents the measured bond strength of the exterior paints along with the mean, standard deviation and coefficient of variation for each group of five measurements. In method I, all failures occurred at the primer/paint interface. Tests \#II and \#14 in Method II were excluded because the epoxy adhesive failed. The mean values of the sets of five measurements (Table 3) were between $6.45 \mathrm{Mpa}$ and $8.26 \mathrm{Mpa}$ (930 psi and $1200 \mathrm{psi}$ ). The coefficients of variation ranged from 2 percent to 13 percent. The grand mean values by Method I and II were $7.61 \mathrm{Mpa}$ and 6.79 Mpa, respectively. The grand coefficient of variation was 14 percent for Method I, while that of Method II was 8 percent. The 
difference in variation can be seen in Figure 12, where the plotted values from Method I spread over a wider range.

A statistical test [20] was carried out to examine whether the grand mean values by Method I and II could be regarded as different. The calculated t-value was 1.28 , which is less than the 2.06 required to indicate that the two groups have different averages at a significance level of 5 percent $\left(\mathrm{T}_{0.05}=2.06\right.$ at 26 degrees of freedom). Their difference, therefore, was not statistically significant; the exterior paints tested yielded virtually an equal strength under the two conditions.

The bond strength of the interior paint is presented in Table 4. The mean values of five measurements ranged from $7.34 \mathrm{Mpa}$ (1060 psi) to $10.84 \mathrm{Mpa}$ (1570 psi). The grand mean of Method I was $9.61 \mathrm{Mpa}$ (1390 psi) and that of Method II was $8.89 \mathrm{Mpa} \mathrm{(1290}$ psi). As for the deviation of the measured values, the strength of the interior paint had a greater coefficient of variation than that of the exterior paint. The coefficient of variation. amounted to 23 percent in Method II.

A statistical test [20] to examine whether the difference in the grand averages in Methods I and II was statistically significant was made for interior paint. The calculated t-value was 0.94 , which is less than 2.06 to claim that two groups have different averages at the 5 percent significance level $\left(\mathrm{T}_{0.05}=2.06\right.$ at 25 
degrees of freedom). It is concluded that, for the both paints tested, bond strength to the substrate was not dependent on the two methods used in the experiments.

The results of strength measurements are summarized in Figure 13, which presents the total strength frequency (Method I and II). The values obtained in these tests had a wider variation than those of previous experiments with other typical paints in which the coefficients of variation were from 10 to 12 percent [19]. It should be noted that this variation could be caused by the unevenness of the sample paint itself as well as by measurement errors. 
5. PRELIMINARY ASSESSMENT OF A SEMI-NONDESTRUCTIVE PULL-OFF TEST

Since a failure occurs at the weakest plane in the test assembly in pull-off testing, it was postulated that the pull off test might be able to be used as a "semi-nondestructive" proof test method. If, for example, the bond strength between the paint and adhesive is slightly less than the minimum required for bond strength of the paint to the substrate, the test could be used to ensure that the paint to the substrate bond is acceptable. This use of pull-off test could provide and effective go/no-go test. Developing such a test involves determining a means to reduce the bond strength of paint/adhesive interface to the level which is equal to the minimum paint bond required. The following preliminary experiments were carried out to verify if the foregoing use of the pull off test is feasible.

\subsection{Description of Method}

The method, the paint test samples, and the apparatus used were the same as those used in the experiment described earlier. The procedure was almost the same, except that certain materials were applied on the paints to reduce the bond strength of adhesive. (Here, we call them "bond controllers".) First, a paper mask with a hole of the same diameter as the button was placed on the paint. Then, one of the three following bond controllers was applied over the paint:

1) a thin layer of wax for polishing shoes,

2) marks from a red colored pencil, or 
3) marks from a rubber eraser.

For bond controller 1, a 24-hour epoxy adhesive was used with a 40-minute cure at $70^{\circ} \mathrm{C}$ as in the previous experiment. A fastsetting, five minute epoxy adhesive was used with the bond controllers 2 and 3 . The adhesives were cured for one hour at room temperature (approx. $21^{\circ} \mathrm{C}$ ). The fast setting epoxy was used on the assumption that it could be more convenient in practice if samples do not have to be heated for curing before testing.

\subsection{Results}

Table 5 presents the bond strength and the percentage of adhesives left on the tested surface after the pull-off test.

When wax and the 24-hour epoxy were employed, no adhesive was left on the paints. The average bond strength of the exterior and interior paint was $2.80 \mathrm{MPa}$ and $5.11 \mathrm{MPa}$, respectively. Their ratios to the bond strength measured previously in chapter 4 were 39 percent (the exterior paint) and 55 percent (the interior paint).

Red pencil and five-minute epoxy reduced the strength to 27 percent (the exterior paint) or 16 percent (the interior paint) of the previous bond strength. No adhesive remained on the paint. The first test result on the exterior paint is not listed because the loading button came off before testing. 
A part of the adhesive remained on the paint in the third experiment where the surface was rubbed with a eraser. The breaking stresses after applying the bond controller were 61 and 49 percent of the initial bond strenghs of the exterior and interior paints, respectively. It is noted that the variation in the breaking stress was small in spite of the difference in the amount of adhesives left on surface among the test locations. This indicated that the cohesive strength of five-minute adhesive was approximately the same as that of the interface tested in the third experiment.

Two of the three bond controller methods were successful in making adhesives delaminate from the paint surface. Although a slight stain remained on the paint after the test, cleaning removed the stain. 
6. SUMMARY AND CONCLUSIONS

This study was carried out to identify or develop an improved test method for evaluating the adequacy of paint adhesion on tactical rigid wall shelters. Criteria for use in assuring the adequacy of the paint adhesion were developed. It is expected that a method which fulfills these requirements will replace the present test methods, i.e., tape pull-off or knife lift. The following is a summary of the study:

- In the identification of currently available methods, paint adhesion test methods were reviewed. Both destructive and non-destructive methods were investigated in terms of their compliance with the criteria. Among the destructive methods were the button pull-off test; the moment test; the tape test; the blister test; the ultracentrifugal test; the lapshear test; the ring shear method; the indentation test; and the scratch test. The non-destructive methods included: the ultrasonic methods; the Fokker bond tester; laser pulse method; and infrared thermography.

- Of all the methods investigated, the button pull-off test was found to be the most suitable in-situ test method, a main shortcoming being that it is destructive. Its major advantages are that:

1) it is simplest and most fundamental in its principle of measurement; thus a measure of bond strength is obtained directly without calibration;

2 ) it is relatively error-free since prior studies have improved the test apparatus and have eliminated most of the factors which cause errors in measurement, and

3) it has the potential for identifying the weakest interface or layer within a paint system.

- Among the non-destructive methods, the ultrasonic method and thermography were the most promising in assessing the paint adhesion to the substrate. But their use has been limited primarily to detecting voids rather than measuring bond strength. Further studies are needed to assess the potential usefulness of the two non-destructive methods. 
In accordance with the conclusions drawn from the review of paint adhesion tests, the button pull-off test was examined in two series of preliminary experiments using the test samples of painted aluminum alloy received from a shelter manufacturer. The bond strength of painted samples was measured with a self-aligning bond tester, using two slightly different fixtures. In both methods the locus of failure was the primer/paint interface for both paints. The average strength by the two methods were $7.27 \mathrm{Mpa}$ (the exterior paint) and $9.29 \mathrm{Mpa}$ (the interior paint). Method I yielded a slightly higher strength than Method II but the difference was not statistically significant. The overall dispersion of measured strength was greater than expected in the interior paint. It was not clear if this was due to the errors in measurement or if it reflected actual variation in the strength of the interior paint sample.

- A second series of experiments was carried out to examine the feasibility of using the button pull off test as a proof test to ensure that the paint to substrate bond is, at least, a minimum acceptable level. Wax, a red pencil, and an eraser were the "bond controllers" tested to examine whether they could obstruct the bond so that adhesive would not remain on the paints after the pull-off test. Using wax or a red pencil was successful; the button came off at a tensile stress almost one half of the paint bond strength, leaving nothing but a cleanable stain. Rubbing the paint surface with an eraser prior to testing was less effective than the other two bond controllers.

\section{RECOMMENDATIONS FOR FUTURE RESEARCH}

As was described in the conclusions, the test method most closely meeting the essential criteria is the button pull-off test. The preliminary experiments indicated the test can be developed into a proof test. From the viewpoint of this project, the improved pull-off test will be the most attractive because it will not damage the shelter paint provided its bond strength is above a predetermined value. Therefore, it is recommended that future research focus on developing the pull-off test to suit the assessment of the bond quality carried out in a shelter factory. This requires identifying a means to control the adhesive/paint 
bond strength and determining the minimum acceptable paint to substrate strength required for field use.

As for non-destructive testing, the ultrasonic method and infrared thermography have the potential for assessing paint to substrate bond quality. There is need for research on these new techniques, and it is recommended that a feasibility study be made.

The recommendations on the basis of the study are as follows:

I. Establish a technical basis for a minimum acceptable bond strength.

Bond strength of actual panels should be measured with the button pull-off test and compared to performance in actual service. Based on the results, a minimum acceptable strength should be determined for the exterior and the interior paint. At the same time, paints with a low bond quality should be tested to provide data for a minimum acceptable value; in other words, a criteria for future go/no-go testing.

II. Develop and standardize an improved pull-off method.

Carry out systematic experiments for developing a proof-type pull-off test method. The main objective of the experiments would be to find a technique for effectively and constantly reducing the bond strength at the adhesive/paint interface. In designing the experiments, consideration should be taken into account that the test will be carried out in a factory. After identifying an adequate procedure, the improved pulloff method should be standardized for use on site.

III. Carry out a feasibility study on non-destructive methods.

In an experimental study, the ultrasonic methods and infrared thermography should be examined in terms of their ability to detect the effectiveness of bond between the paint and the substrate. 
This study was supported by the U.S. Army Natick Research, Development and Research center. The authors extend their thanks to David Mikelson for his assistance in providing research support and the painted specimens. The authors also thank Geoffrey Frohnsdorff, Mary McKnight, and Robert Mathey for their review of this report.

\section{REFERENCES}

1. G.P. Anderson, S.J. Bennet and K.L. Devries (eds.), Analysis and Testing of Adhesive Bonds, Academic Press, New York, 1977.

2. S. Paul, Surface Coatings, John Wiley \& Sons, Chichester, 1985.

3. J. Sickfeld, "Pull-off Test, Internationally standardized Method for Adhesion Testing -- Assessment of the Relevance of Test Results," Adhesion Aspects of Polymeric Coatings (ed. Mittal, Proceedings of the Symposium on Adhesion Aspects of Polymeric Coatings), Plenum Press, New York, 1983.

4. "Standard Method for Pull-off Strength of Coatings Using Portable Adhesion Testers," ASTM D4541-85, Annual Book of ASTM Standards, American Society for Testing and Materials, Philadelphia, PA, 1988.

5. "Paints and Varnishes -- Pull-off Test for Adhesion," Iso \#4624-1978(E), International organization for standardization, Brussels.

6. J. Stone, "Paint Adhesion on a Scribed Surface: The Pass Test," Journal of Paint Technology, Vol. 41, No. 539, December 1969.

7. G.V. Calder, F.C. Hansen and A. Parra, "Quantifying the Tape Adhesion Test," Adhesion Aspects of Polymeric Coatings (ed. Mittal, Proceedings of the Symposium on Adhesion Aspects of Polymeric Coatings), Plenum Press, New York, 1983.

8. "Standard Test Method for Measuring Adhesion by Tape Test," ASTM D3359-87, Annual Book of ASTM Standards, American Society for Testing Materials, Philadelphia, PA, 1988. 
9. D.S. Lin, "The Adhesion of Metal Films to Glass and Magnesium Oxide in Tangential Shear," Journal of Physics: Applied Physics, 1971, Vol. 4 .

10. J.W. Dini and H.R. Johnson, "Techniques for Quantitatively Measuring Adhesion of Coatings," Metal Finishing, March 1977.

11. "Standard Test Method for Adhesion of Organic Coating by Scrape Adhesion," ASTM D2197, Annual Book of ASTM Standards, American Society for Testing and Materials, Philadelphia, PA 1988 .

12. P.A. Engel and G.C. Pedroza, "Indentation-debounding Test for Adhered Thin Polymer Layers," Adhesion Aspects of Polymeric Coatings (ed. Mittal Proceedings of the Symposium on Adhesion Aspects of Polymeric Coatings), Plenum Press, New York, 1983.

13. J. Szilard, Ultrasonic Testing, John Wiley \& Sons, New York, 1982 .

14. B.R. Schliekelmann, "Nondestructive Testing of AdhesiveBonded Metal Structures, Part 1 and 2," Adhesive Age, MayJune 1964.

15. M.S. Good, J.B. Nestleroth and J.L. Rose, "Ultrasonic Inspection Potential for Polymeric Coatings," Adhesion Aspects of Polymeric Coatings (ed. Mittal, Proceedings of the Symposium on Adhesion Aspects of Polymeric Coatings), Plenum Press, New York, 1983.

16. H. Kawasaki and S. Suzuki, "Nondestructive Measurement of Coated Film-Steel Bond Strength Using Ultrasonic Resonance Frequency Method," Tetsu to Hagane, Vol. 72 (1986), No. 11.

17. Anon., "Monitoring of Adhesion Strength between Materials by Photo-Acoustic Pulse Generation at or near the Interface," IBM Technical Disclosure Bulletin, Vol. 28, No. 2, July 1985.

18. D.W. Wilson and S.I. Guceri, "Thermographic Nondestructive Evaluation of Steel-Polypropylene Laminates," Journal of Nondestructive Evaluation, Vol. 4, No. 1, 1984 .

19. B.E. Dom, H.E. Evans and D.M. Torres, "Thermographic Detection of Polymer/Metal Adhesion Failures, "Adhesion Aspects of Polymeric Coatings (ed. Mittal, Proceedings of the Symposium on Adhesion Aspects of Polymeric Coatings), Plenum Press, New York, 1983.

20. M.G. Natrella, Experimental Statistics, National Bureau of Standards (now National Institute of Standards and Technology), October 1966. 
21. J.F. Seiler, M.E. McKnight, and L.W. Masters, "Development of a Test Apparatus and Method for Measuring Adhesion of Protective Coatings," NBSIR 82-2535, National Bureau of Standards (now the National Institute of Standards and Technology), July 1982 .

22. K.A. Mittal (ed.), "Adhesion Measurement: Recent progress, Unsolved Problems and Prospects," Measurement of Thin Films, Thick Films, and Bulk Coatings, ASTM Special Technical

Publication 640, American Society for Testing and Materials, Philadelphia, PA 1978.

23. J. Valli, "A Review of Adhesion Test Methods for Thin Hard Coatings," Journal of Vacuum Science and Technology, A4(6), 1986.

24. A.J. Kinloch, Adhesion and Adhesives, Chapman and Hall, New York, 1987. 
Table 1. Destructive Test Methods to Evaluate Bond Strength of Paints Name Description of the method and commentary

\section{Using a stress applied normal to paint film}

Button pull-off test $[1-3,19]$

Description: A metallic button is adhered to the surface of the paint. Then the button is pulled perpendicular to the paint/substrate bond line to determine the stress at which a detachment occurs.

Commentary: o Many studies have been made on this test: equipment has been developed to ensure reproducibility and to enable in-situ evaluation.

- The solvents in the adhesives may penetrate and affect the paint properties.

- The stress generated during the curing of the adhesive may affect the test value.

- Alignment of the pulling jig must be accurate to attain reproducible results.

- ASTM D4541, "Standard Method for Pull-off Strength of coatings Using Portable Adhesion Testers," specifies the test method as well as the configuration.

- ISO \#4624, "Paints and Varnishes -- Pull-off Test for Adhesion," proposes two types of test assemblies.

Moment (Topple) test [2]

Description: Force is applied to a rod adhered to the paint. The moment required to detach the paint from the substrate is measured.

Commentary: o The principle of measurement to pull the paint off the substrate is the same as that of the pull-off test. The apparatus is comparatively simple.

Tape test $[1,2,6-8]$

Description: There are two types of tape test in ASTM D3359, "Standard Test Method for Measuring Adhesion by Tape Test": $\mathrm{X}$-cut tape test

A pressure-sensitive tape is placed on the paint and then peeled up. The extent of removal of paint from the substrate gives the assessment of adhesion. Cross-cut tape test

Cuts are made over the paint to form a grid, either one or two millimeters apart, depending on the thickness of the paint. A pressure-sensitive tape is placed on the paint and peeled up. The portion of the paint detached within the grid indicates the degree of adhesion.

Commentary: o The procedures are simple and need only a short time and the costs of carrying them out are relatively low.

- The methods are not quantitative but semi-quantitative classifications are presented. 
Table 1. Destructive Test Methods to Evaluate Bond Strength of Paints (continued)

Name Description of the method and commentary

Blister test [2]

Description:

The sample paint is applied on a disk with an opening. Compressed fluid is forced to the specimen through the opening. Since the unbonded region is pressurized, the paint forms a blister. The adhesive strength is calculated from the critical pressure that initiates the adhesive failure along the paint/substrate interface.

Commentary: o Application to the field sample is difficult because the substrate has to have an opening.

Ultracentrifugal method [2]

Description: A painted test plate is suspended magnetically in vacuum and rotated at increasing speed until the paint is detached by the centrifugal force.

Commentary: o specimens have to be sampled from the object to be tested.

- The test apparatus is complicated. The substrate must be steel in order to be suspended in a magnetic field.

II. Using a stress applied parallel to the paint film

Lap-shear method [9]

Description:

An attachment is bonded to the surface of the sample paint and subjected to a shear force applied parallel to the paint bond line.

Commentary: o Few studies have been done on this test.

- This method has the same limitation as the pull-off test due to the application of adhesives.

Ring shear method [10]

Description: A cylindrical rod is covered with a paint film with a predetermined width and thickness. The rod is then forced through a hardened steel die that has a hole larger in diameter than the rod but smaller than that of the rod plus paint. The adhesion of paint is measured as the shear stress required to cause failure.

Commentary: o The preparation of paint sample needs accuracy in dimensions, in particular, of the thickness of the paint film.

Indentation test [12]

Description: An indenter is pushed on the paint surface under increasing normal load. The stress required to break the bond between the paint and the substrate is measured.

Commentary: o This test can be done with a conventional hardness tester.

- The scratch test is a modification of this method.

- Few studies have been made on this test. 
Table 1. Destructive Test Methods to Evaluate Bond Strength of Paints (continued)

Name Description of the method and commentary

Scratch test [11] Description:

A rounded tip is drawn across the paint with a gradually increasing vertical load. The movement of the point produces plastic deformation of the surface, thus causing a shear stress. The critical load at which the paint is removed is measured. $\begin{aligned} \text { Commentary: } & \text { Factors affecting the test result (substrate hardness, } \\ & \text { paint thickness, surface roughness, etc.) have not been }\end{aligned}$ fully studied.

- ASTM D2197, "Standard Test Method for Adhesion of Organic Coating by Scrape Adhesion," specifies the tester and the procedure. 
Table 2. Non-destructive Test Method to Evaluate Bond Quality of Paints

Name Description of the method and commentary

Ultrasonic method [13-17]

Description: Transmitting and a receiving transducers are acoustically connected to the test sample. Ultrasonic pulses are transmitted and are reflected by discontinuities of acoustic properties in materials. These discontinuities include the surfaces of the test sample, interfaces of different materials, and most importantly the defects in the test sample. Thus, bond failures are detected by analyzing the received pulses. The ultrasonic nondestructive test technique is categorized in three types; transmission method, resonance technique, and pulse echo technique (Figure 8.)

Commentary: o The transducers usually need coupling media (e.g., water, oil) to be acoustically connected to the sample. This fact tends to be a practical disadvantage of the method.

- Little has been reported on the detection of the bond quality of paints.

Fokker bond tester [14]

Description: The resonance phenomena of adhesively-bonded materials to mechanical vibrations depend on the degree of bond between the components. The bond tester measures the change in the frequency (A-value) and the amplitude(Bvalue) of the resonance. The lap shear strength can be estimated with these values.

Commentary: o The tester was originally invented to evaluate the bond strength of adhered metal. Its application to paint bond assessment has not been fully studied.

Laser pulse [17] Description:

Laser pulse applied on paint surface generate acoustic waves which travels through the substrate. Adhesion defects are detected by measuring the ultrasonic waveform at the back side of the substrate.

commentary: o The method is newly developed. Although its potential is high, a shortcoming is that and access to the back side of substrate is required for the measurement.

Infrared thermography $[18,19]$

Description:

Delamination of paints forms a thermally discontinuous region under the paint film. When the surface is heated (or cooled), this results in a higher (or lower) surface temperature than the adjacent area because of retarded heat flow. The locations of bond defects can be seen in a thermal image of the sample with an infrared camera.

Commentary: o This method can be applied to test a relatively large area at a time.

- Little has been reported on the detection of the bond quality or the bond strength of paints. 
Table 3. Bond Strength of Exterior Paint Measured by Pull-off Test

\begin{tabular}{|c|c|c|c|c|c|c|c|}
\hline $\begin{array}{l}\text { Test } \\
\text { Method }\end{array}$ & Group & $\begin{array}{c}\text { Test } \\
\#\end{array}$ & $\begin{array}{l}\text { Individual } \\
\text { Value } \\
\text { (MPa) }\end{array}$ & $\begin{array}{l}\text { Group } \\
\text { Value } \\
\text { (MPa) }\end{array}$ & & $\begin{array}{l}\text { Total } \\
\text { Value } \\
\text { (MPa) }\end{array}$ & \\
\hline \multirow[t]{3}{*}{$\begin{array}{c}\text { Method } \\
I\end{array}$} & Group & $\begin{array}{l}1 \\
2 \\
3 \\
4 \\
5\end{array}$ & $\begin{array}{l}7.52 \\
8.34 \\
8.34 \\
8.34 \\
7.52\end{array}$ & $\begin{array}{l}\text { MEAN } \\
\text { S.D. } \\
\text { C.V. }\end{array}$ & $\begin{array}{l}=8.01 \\
=0.41 \\
=5 \%\end{array}$ & $\begin{array}{l}\text { MEAN } \\
\text { S.D. } \\
\text { C.V. }\end{array}$ & $\begin{array}{l}=7.61 \\
=1.09 \\
=14 \%\end{array}$ \\
\hline & Group & $\begin{array}{l}6 \\
7 \\
8 \\
9 \\
10\end{array}$ & $\begin{array}{l}7.31 \\
5.65 \\
7.72 \\
6.55 \\
5.52\end{array}$ & $\begin{array}{l}\text { MEAN } \\
\text { S.D. } \\
\text { C.V. }\end{array}$ & $\begin{array}{l}=6.55 \\
=0.87 \\
=13 \%\end{array}$ & & \\
\hline & Group & $\begin{array}{l}11 \\
12 \\
13 \\
14 \\
15\end{array}$ & $\begin{array}{l}6.90 \\
8.27 \\
7.58 \\
9.72 \\
8.83\end{array}$ & $\begin{array}{l}\text { MEAN } \\
S . D . \\
C . V .\end{array}$ & $\begin{array}{l}=8.26 \\
=0.98 \\
=12 \%\end{array}$ & & \\
\hline \multirow[t]{3}{*}{$\begin{array}{l}\text { Method } \\
\text { II }\end{array}$} & Group & $\begin{array}{l}1 \\
2 \\
3 \\
4 \\
5\end{array}$ & $\begin{array}{l}7.10 \\
6.27 \\
6.55 \\
6.14 \\
6.21\end{array}$ & $\begin{array}{l}\text { MEAN } \\
\text { S.D. } \\
\text { C.V. }\end{array}$ & $\begin{array}{l}=6.45 \\
=0.35 \\
=5 \%\end{array}$ & $\begin{array}{l}\text { MEAN } \\
\text { S.D. } \\
\text { C.V. }\end{array}$ & $\begin{array}{l}=6.79 \\
=0.53 \\
=8 \%\end{array}$ \\
\hline & Group & $\begin{array}{l}6 \\
7 \\
8 \\
9 \\
10\end{array}$ & $\begin{array}{l}5.79 \\
7.38 \\
7.52 \\
7.31 \\
7.31\end{array}$ & $\begin{array}{l}\text { MEAN } \\
\text { S.D. } \\
\text { C.V. }\end{array}$ & $\begin{array}{l}=7.06 \\
=0.64 \\
=9 \%\end{array}$ & & \\
\hline & Group & $\begin{array}{l}11 \\
12 \\
13 \\
14 \\
15\end{array}$ & $\begin{array}{l}---* \\
7.03 \\
6.96 \\
---* * \\
6.76\end{array}$ & $\begin{array}{l}\text { MEAN } \\
\text { S.D. } \\
\text { C.V. }\end{array}$ & $\begin{array}{l}=6.92 \\
=0.12 \\
=2 \%\end{array}$ & & \\
\hline
\end{tabular}

S.D.: Standard Deviation

C.V.: Coefficient of Variation (S.D./MEAN $\times 100 \%$ )

* : The measured value was excluded because the adhesive partially failed. 
Table 4. Bond Strength of Interior Paint Measured by Pull-off Test

\begin{tabular}{|c|c|c|c|c|c|c|c|}
\hline $\begin{array}{l}\text { Test } \\
\text { Method }\end{array}$ & Group & $\begin{array}{c}\text { Test } \\
\#\end{array}$ & $\begin{array}{l}\text { Individual } \\
\text { Value } \\
\text { (MPa) }\end{array}$ & $\begin{array}{l}\text { Group } \\
\text { Value } \\
\text { (MPa) }\end{array}$ & & $\begin{array}{l}\text { Total } \\
\text { Value } \\
\text { (MPa) }\end{array}$ & \\
\hline \multirow[t]{3}{*}{$\begin{array}{l}\text { Method } \\
I\end{array}$} & Group & $\begin{array}{l}1 \\
2 \\
3 \\
4 \\
5\end{array}$ & $\begin{array}{r}10.07 \\
8.27 \\
8.48 \\
8.83 \\
7.79\end{array}$ & $\begin{array}{l}\text { MEAN }= \\
\text { S.D. }= \\
\text { C.V. }=\end{array}$ & $\begin{array}{l}=8.69 \\
=0.77 \\
=9 \%\end{array}$ & $\begin{array}{l}\text { MEAN } \\
\text { S.D. } \\
\text { C.V. }\end{array}$ & $\begin{array}{l}=9.61 \\
=1.71 \\
=18 \%\end{array}$ \\
\hline & Group & $\begin{array}{l}6 \\
7 \\
8 \\
9 \\
10\end{array}$ & $\begin{array}{r}7.38 \\
9.58 \\
10.00 \\
9.58 \\
9.93\end{array}$ & $\begin{array}{l}\text { MEAN }= \\
S \cdot D .= \\
C \cdot V_{.}=\end{array}$ & $\begin{array}{l}=9.29 \\
=0.97 \\
=10 \%\end{array}$ & & \\
\hline & Group & $\begin{array}{l}11 \\
12 \\
13 \\
14 \\
15\end{array}$ & $\begin{array}{r}13.86 \\
10.27 \\
8.14 \\
12.82 \\
9.10\end{array}$ & $\begin{array}{l}\text { MEAN }= \\
\text { S.D. }= \\
\text { C.V. }=\end{array}$ & $\begin{array}{l}=10.84 \\
=2.18 \\
=20 \%\end{array}$ & & ' \\
\hline \multirow[t]{3}{*}{ Method } & Group & $\begin{array}{l}1 \\
2 \\
3 \\
4 \\
5\end{array}$ & $\begin{array}{l}5.65 \\
9.24 \\
7.03 \\
7.17 \\
7.58\end{array}$ & $\begin{array}{l}\text { MEAN = } \\
\text { S.D. }= \\
\text { C.V. }=\end{array}$ & $\begin{array}{l}=7.34 \\
=1.15 \\
=16 \%\end{array}$ & $\begin{array}{l}\text { MEAN } \\
\text { S.D. } \\
\text { C.V. }\end{array}$ & $\begin{array}{l}=8.88 \\
=2.01 \\
=23 \%\end{array}$ \\
\hline & Group & $\begin{array}{l}6 \\
7 \\
8 \\
9 \\
10\end{array}$ & $\begin{array}{r}8.83 \\
---* \\
---* \\
7.72 \\
10.27\end{array}$ & $\begin{array}{l}\text { MEAN = } \\
\text { S.D. }= \\
\text { C.V. }=\end{array}$ & $\begin{array}{l}=8.94 \\
=1.04 \\
=12 \%\end{array}$ & & \\
\hline & Group & $\begin{array}{l}11 \\
12 \\
13 \\
14 \\
15\end{array}$ & $\begin{array}{r}10.20 \\
12.69 \\
12.00 \\
---* \\
8.21\end{array}$ & $\begin{array}{l}\text { MEAN }= \\
S \cdot D \cdot= \\
C \cdot V \cdot=\end{array}$ & $\begin{array}{l}=10.77 \\
=1.74 \\
=16 \%\end{array}$ & & \\
\hline
\end{tabular}

S.D.: Standard Deviation

C.V.: Coefficient of Variation (S.D./MEAN $\times 100 \%$ )

* : The measured value was excluded because the adhesive partially failed. 


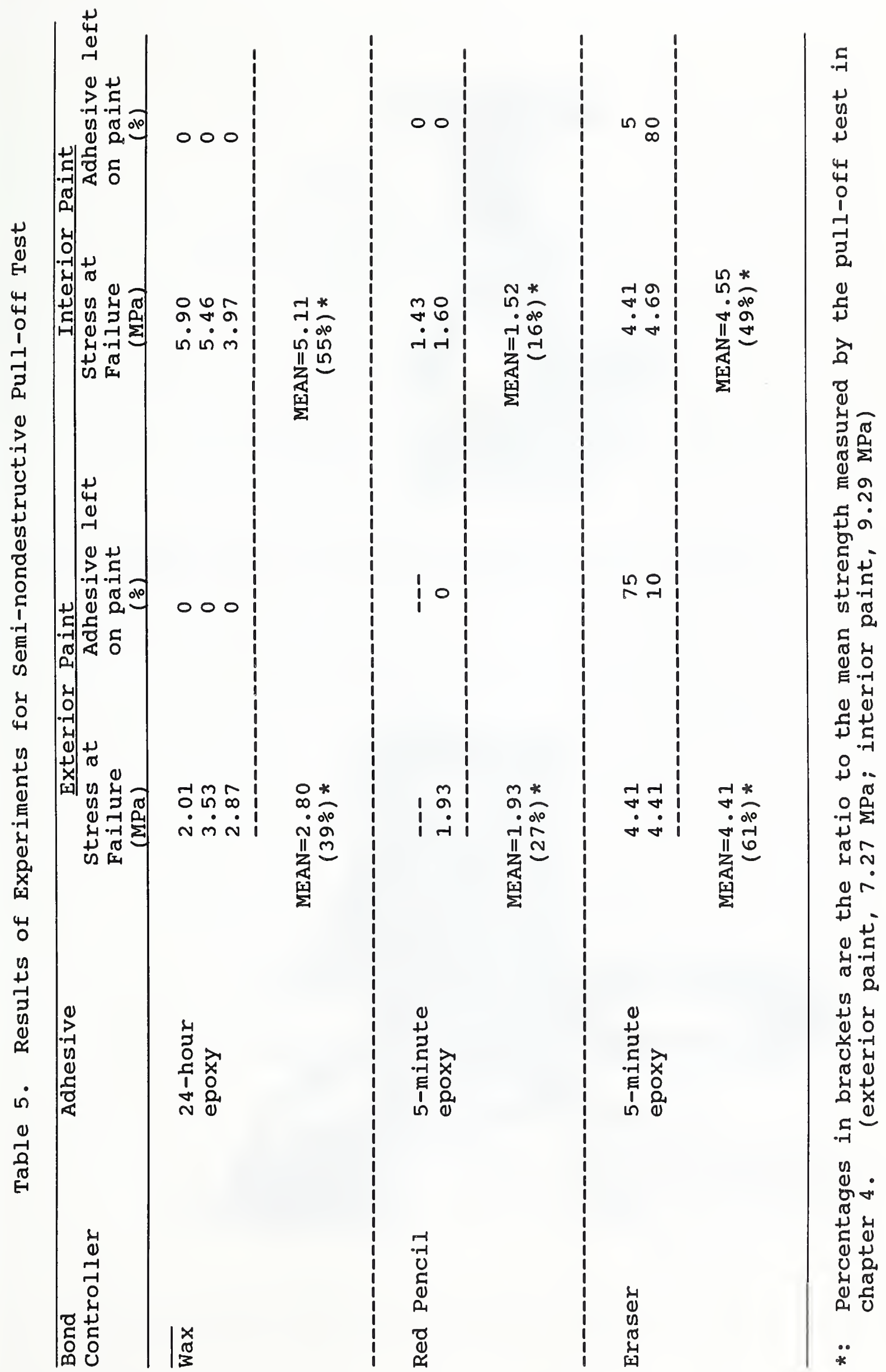




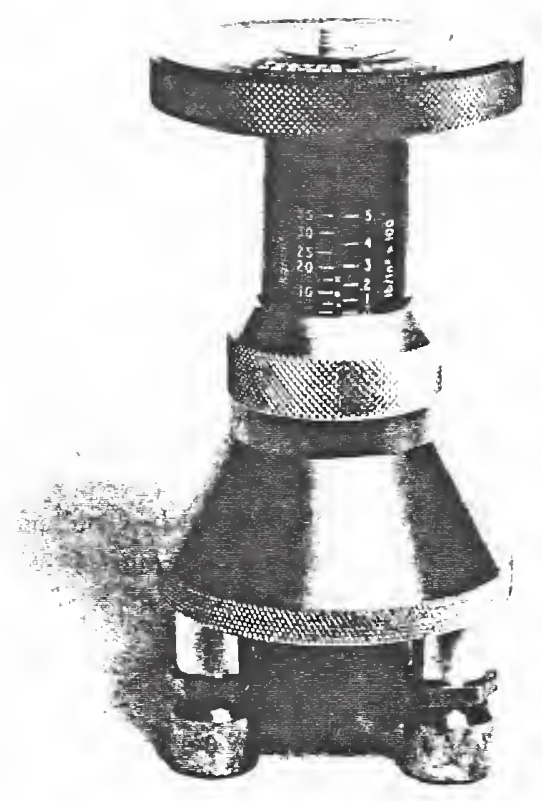

Figure 1. Fixed-Alignment Adhesion Tester for Pull-off Test [4].

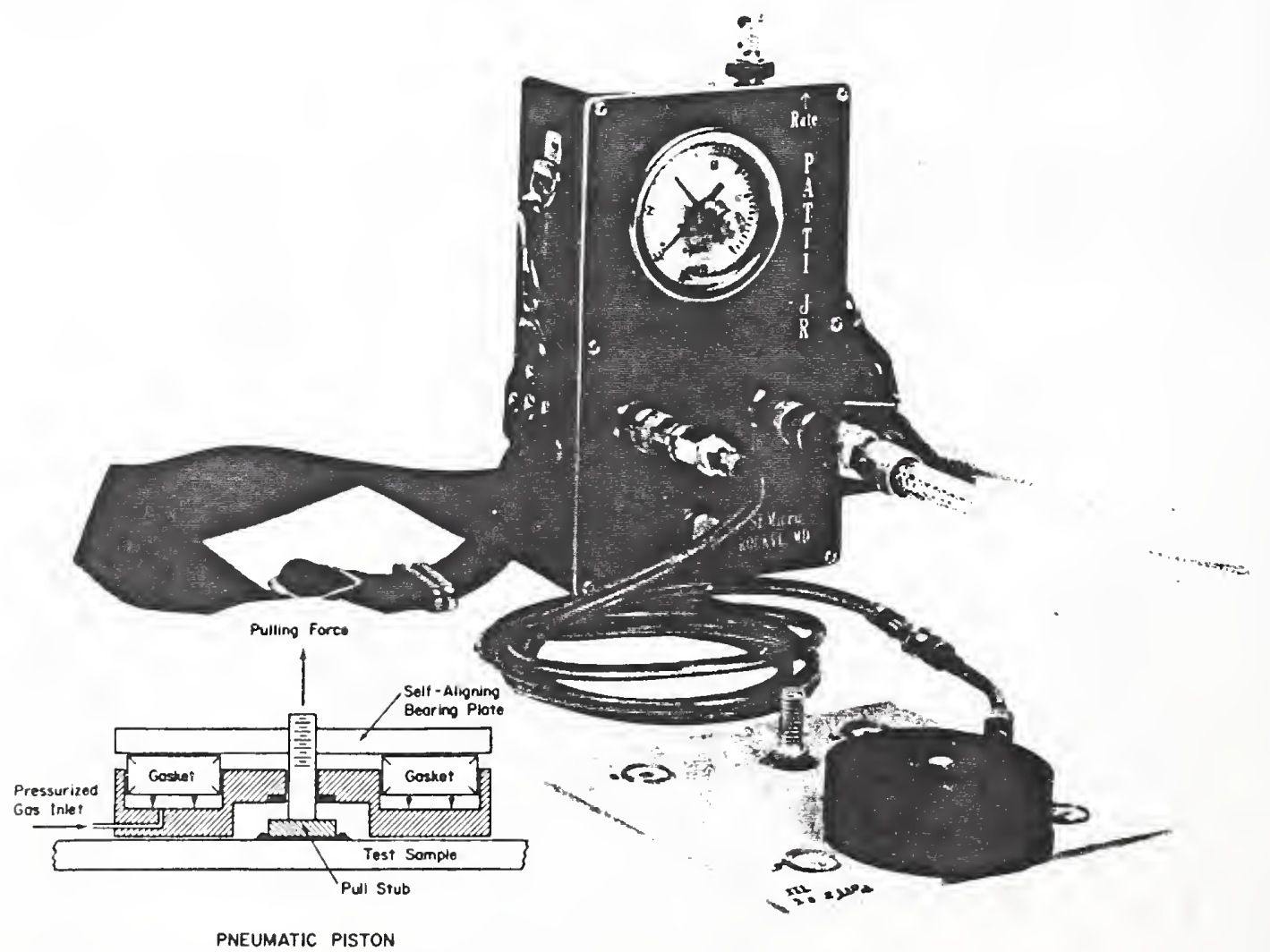

Figure 2. Self-Alignment Adhesion Tester for Pull-off Test [4] • 


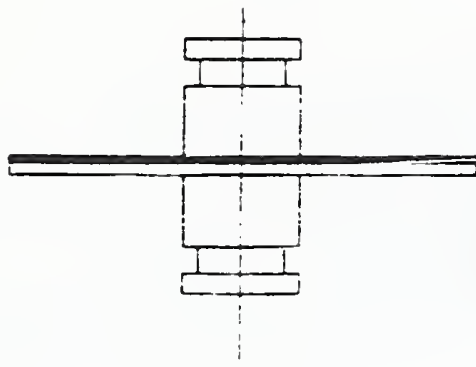

lesi gssembly A

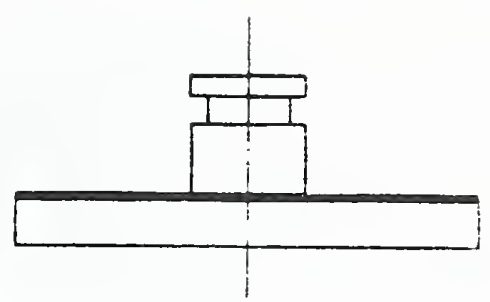

Test assembly 8

Figure 3. Test Assemblies Presented in ISO Standard \#4624 [2].

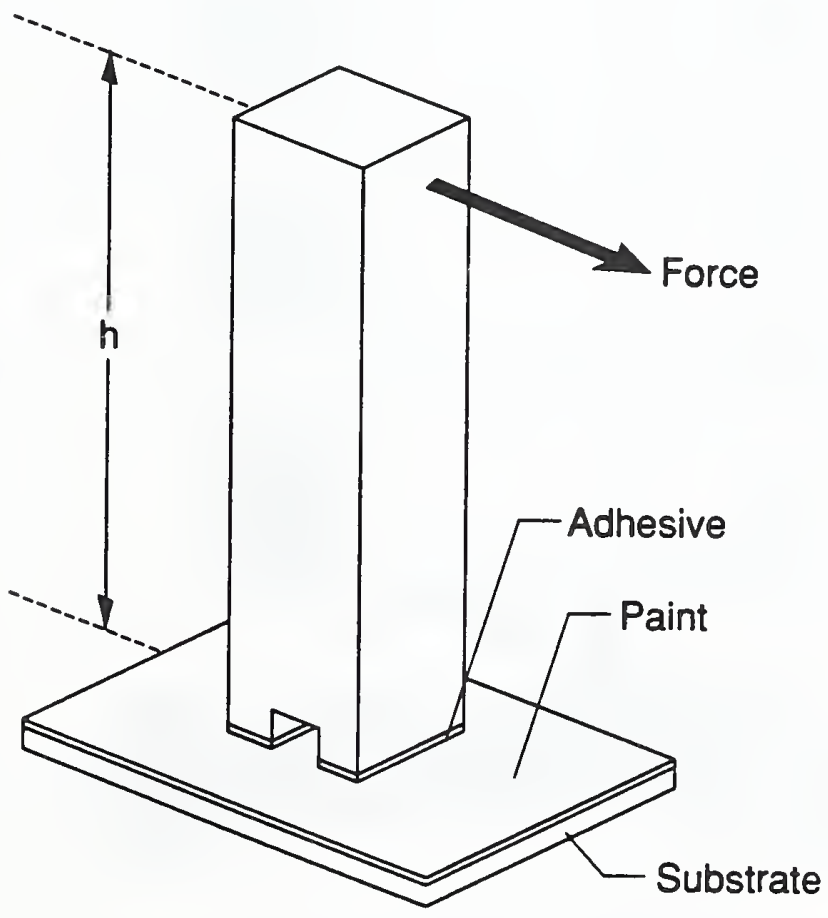

Figure 4. Schematic Diagram of Topple Method. 


\begin{tabular}{|c|c|}
\hline Classillicalion & $\begin{array}{l}\text { Surface of cross-cul area from } \\
\text { which llaking has occurred. } \\
\text { (Example for six paralled cuts) }\end{array}$ \\
\hline 58 & None \\
\hline $4 B$ & $\frac{H+1}{\text { HHt }}$ \\
\hline 38 & 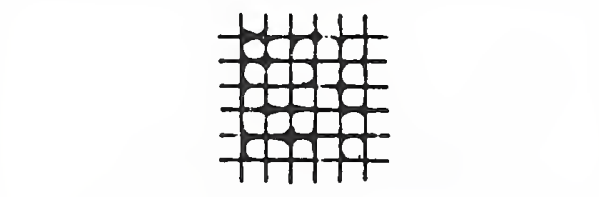 \\
\hline 28 & 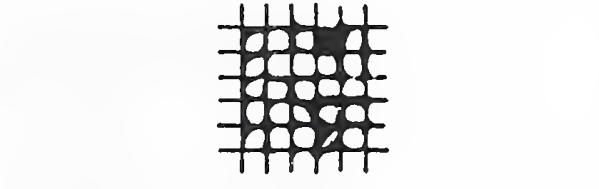 \\
\hline 18 & \\
\hline 08 & Grealer than $65 \%$ \\
\hline
\end{tabular}

Figure 5. Classification of Adhesion Test Results for Cross-Cut Test in ASTM D3359 [8]. 


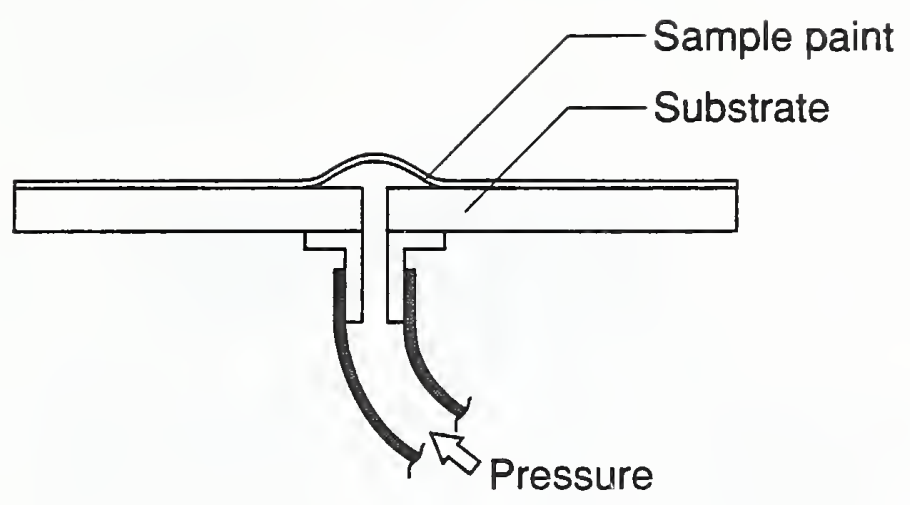

Figure 6. Example of Blister Test configuration.

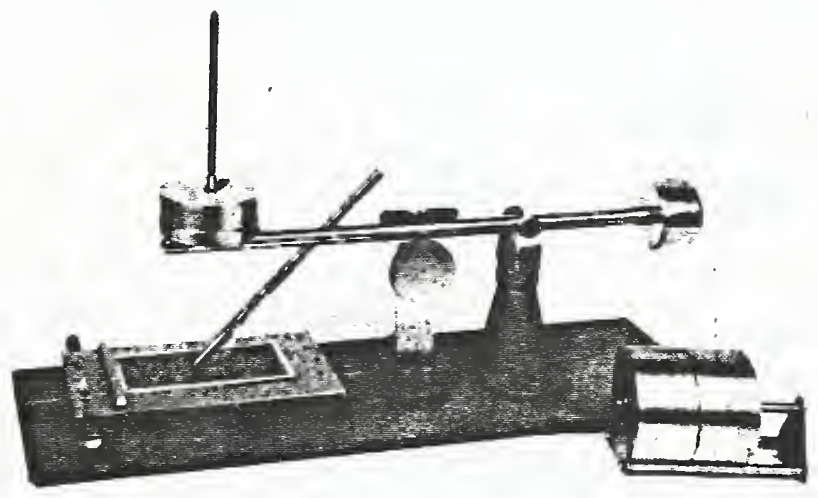

Figure 7. Balanced-Beam Scrape-Adhesion Tester [11]. 


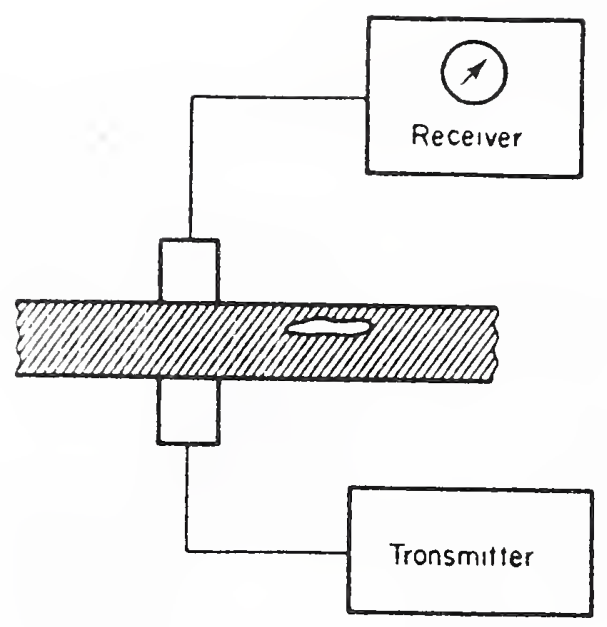

(a) Transmission Method.
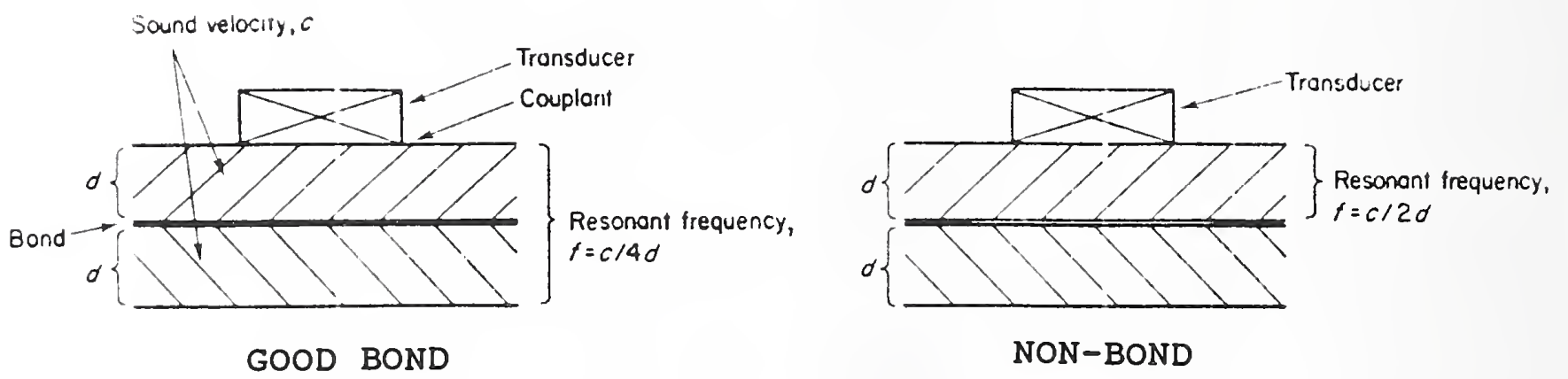

(b) Resonance Technique.

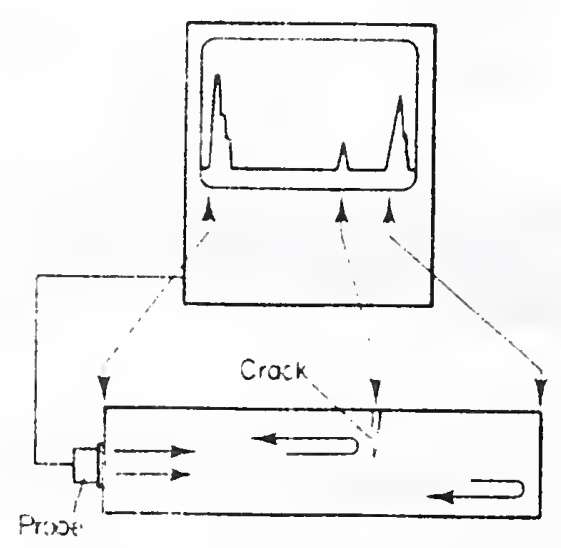

(c) Pulse-Echo Technique.

Figure 8. Three Major Techniques in Ultrasonic Testing [13]. 


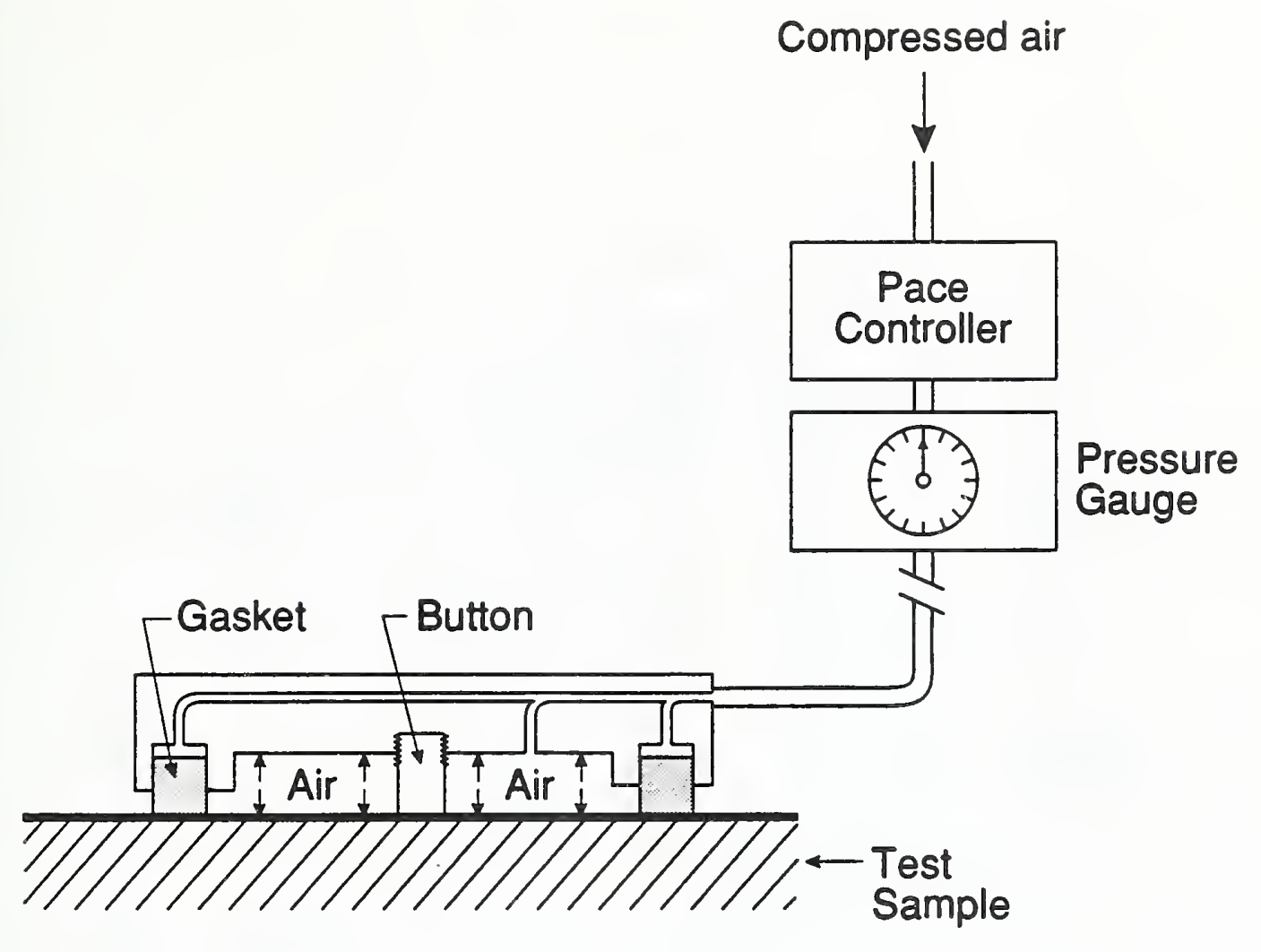

Figure 9. Schematic Diagram of Pull-Off Test.
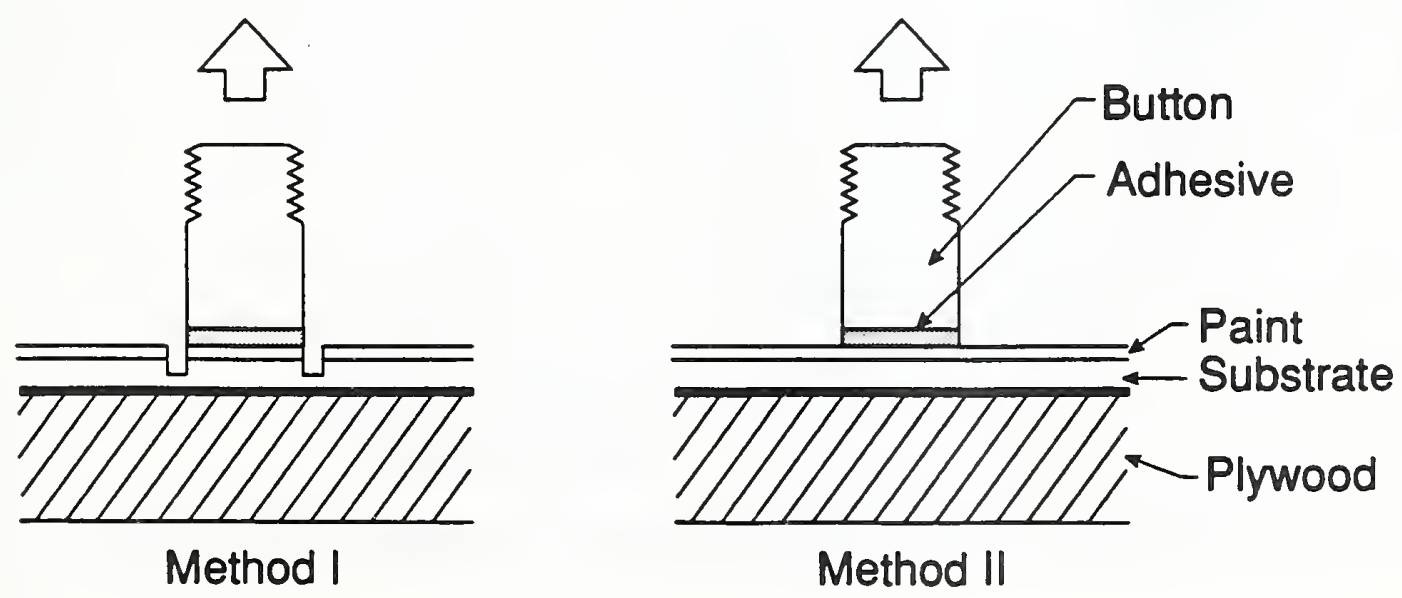

Figure 10. Loading Fixture of Pull-off Test (No Scale). 


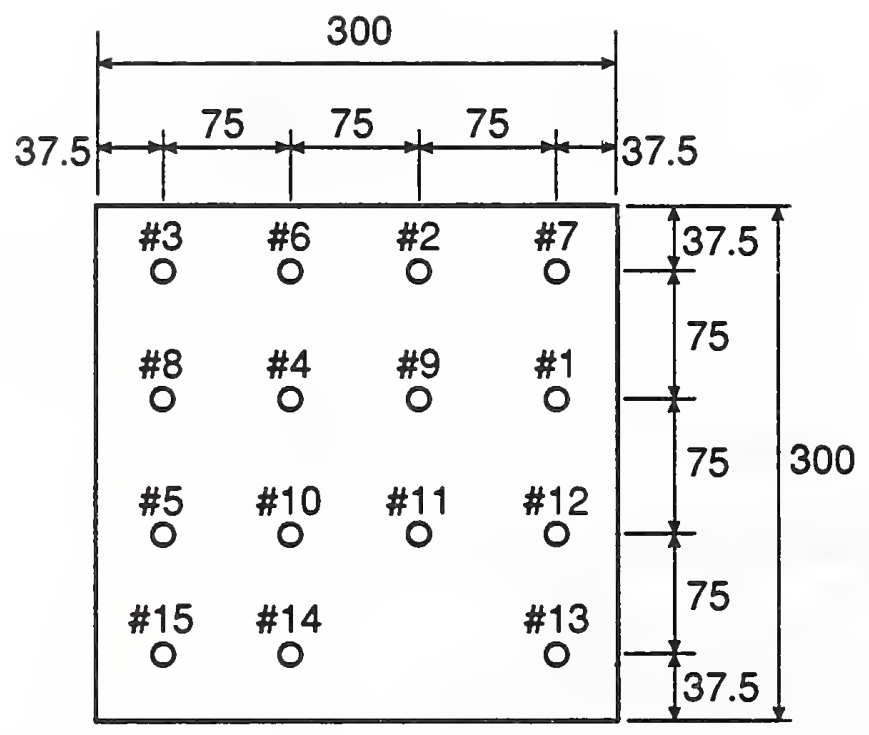

(a) Exterior paint

\begin{tabular}{cccc|}
$\# 1$ & $\# 6$ & $\# 2$ & $\# 7$ \\
0 & 0 & 0 & 0 \\
$\# 8$ & $\# 3$ & $\# 9$ & $\# 5$ \\
0 & 0 & 0 & 0 \\
$\# 4$ & $\# 10$ & $\# 11$ & $\# 12$ \\
0 & 0 & 0 & 0 \\
$\# 15$ & $\# 14$ & & $\# 13$ \\
0 & 0 & & 0 \\
\hline
\end{tabular}

(b) Interior paint

Figure 11. Location of Test Points on Sample Paints (Unit: mm). 


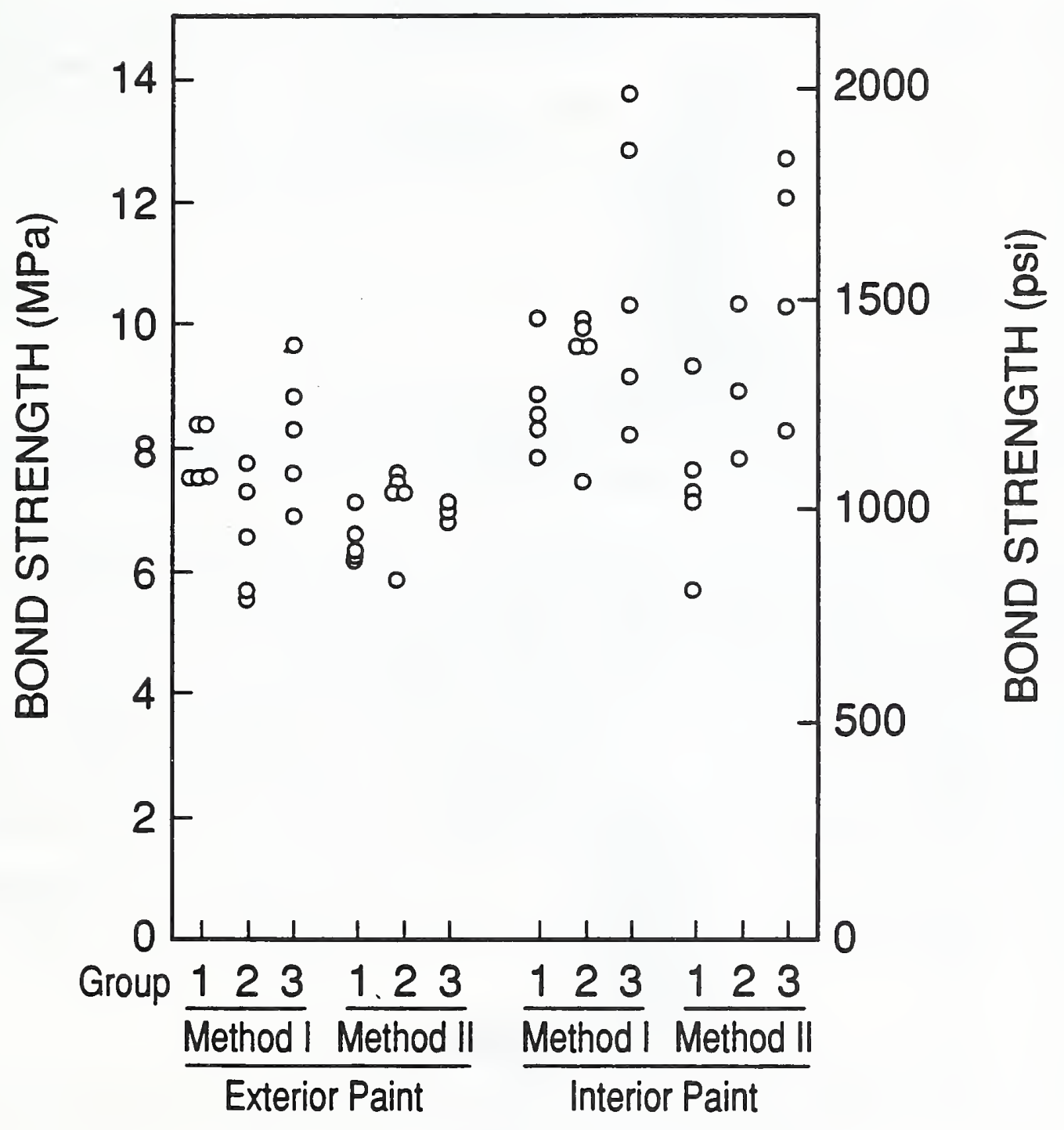

Figure 12. Bond Strength of Sample Paints. 

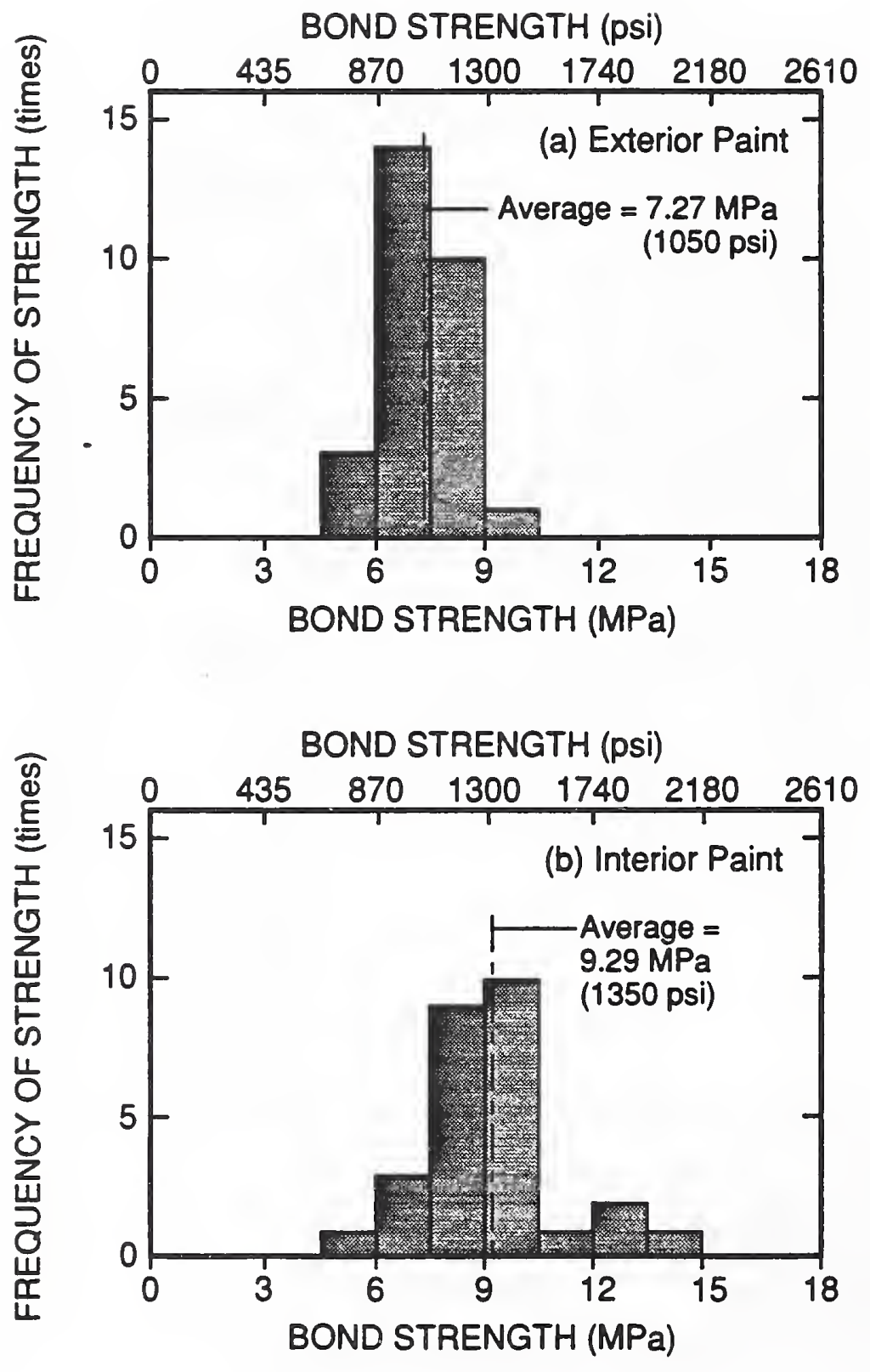

Figure 13. Histogram of Measured Bond strength of Sample Paints. 


\begin{tabular}{|c|c|c|}
\hline \multirow{4}{*}{$\begin{array}{l}\text { NIST-114A } \\
\text { (REV. 3-89) }\end{array}$} & \multirow{4}{*}{$\begin{array}{l}\text { U.S. DEPARTMENT OF COMMERCE } \\
\text { NATIONAL INSTITUTE OF STANDARDS AND TECHNOLOGY } \\
\text { 3IBLIOGRAPHIC DATA SHEET }\end{array}$} & $\begin{array}{l}\text { 1. PUBLICATION OR REPORT MUMBER } \\
\text { NISTIR } 90-4276\end{array}$ \\
\hline & & 2. PERFORMING ORGAMIZATION REPORT NUMBER \\
\hline & & 3. PUBLCATION DATE \\
\hline & & APRIL 1990 \\
\hline
\end{tabular}

4. TITLE AND SUBTITLE

Quality Assurance Tests for Adhesion of Paint on Tactical Rigid Wall Shelters

5. AUTHOR(S)

H. Watanabe, L. Masters, J. Seiler, Jr.

6. PERFORMING ORGAMIZATION (IF JOINT OR OTHER THAN NIST, SEE INSTRUCTIONS)

U.S. DEPARTMENT OF COMMERCE

NATIONAL INSTITUTE OF STAMDARDS AND TECHMOLOGY

GAITHERSBURG, MD 20899

\begin{tabular}{l} 
7. CONTRACT/GRANT NUMBER \\
\hline 8. TYPE OF REPORT AND PERIOD COVERED
\end{tabular}

9. SPONSORING ORGANIZATION NAME AND COMPLETE ADDRESS (STREET, CITY, STATE, ZIP)

U. S. Army Natick Research, Development and Engineering Center

Tactical Shelters Branch

Natick, MA 01760

10. SUPPLEMENTAAY NOTES

DOCUMENT DESCRIBES A COMPUTER PROGRAM; SF-185, FIPS SOFTWARE SUMMARY, IS ATTACHED.

11. ABSTRACT (A 200-WORD OR LESS FACTUAL SUMMARY OF MOST SIOMIFICANT INFORMATION. IF DOCUMENT INCLUDES A SIONIFICANT BIBLOGRAPHY OR UTERATURE SURVEY, MENTION IT HERE.)

This document was prepared at the request of the U.S. Army Natick Research, Development and Engineering Center to provide assistance in identifying or developing a better method(s) for assuring the adequacy of paint adhesion on aluminum-faced sandwich panels of portable rigid wall shelters. The preferred requirements developed for the quality assurance tests are that the tests be quantitative, reliable, suitable for in-situ testing, low cost, and non-destructive.

Currently available methods were surveyed. Both destructive and non-destructive techniques were examined. Among them, a button pull-off test was found to be most advantageous. Preliminary laboratory experiments using a button pull-off test to measure the bond strength of painted specimens provided by a shelter manufacturer showed the average bond strength of the exterior and the interior paints to be $7.27 \mathrm{Mpa}$ (1050 psi) and $9.29 \mathrm{Mpa}$ (1350 psi), respectively. other experiments examined the feasibility of a semi-nondestructive button pull-off techniques, which, by using certain materials to reduce the adhesive/paint bond strength, was capable of testing a paint without damaging it. Two of the three "bond controllers" tested were found to be effective.

The recommendations for future research include: 1) establishing a technical basis for a minimum acceptable bond strength of paint; 2) developing and standardizing a improved button pulloff test; and 3) carrying out a feasibility study on non-destructive methods.

12. KEY WORDS (6 TO 12 ENTRIES; ALPHABETICAL ORDER; CAPITALZE ONLY PROPER NAMES; AND SEPARATE KEY WORDS BY SEMICOLONS)

adhesion; adhesion tests; bond strength; paint; tactical rigid wall shelters; test methods

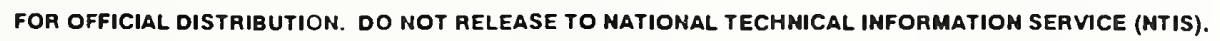

ORDER FROM SUPERINTENDENT OF DOCUMENTS, U.S. GOVERHMENT PRINTIMG OFFICE, WASHINGTON, DC 20402.

ORDER FROM NATIONAL TECHNICAL INFORMATION SERVICE (NTIS), SPRINGFIELD, VA 22161.

14. NUMBER OF PRINTED PAGES

46

15. PRICE

A03 


